\title{
Evaluation of Microalgae Culture in PA and Commercial Urea Media
}

\author{
Pablo Augusto Gulhões ${ }^{1 *}$, Alexia Ananda Santana Simões ${ }^{1}$, Jársia de Melo dos Santos ${ }^{1,2}$, Edna dos Santos Almeida ${ }^{2}$ \\ ${ }^{1}$ Senai Cimatec Technical School, ${ }^{2}$ Senai Cimatec University Center; Salvador,Bahia, Brazil
}

\begin{abstract}
This work aimed to evaluate the growth and cost cultivation of Chlorella sp microalgae in PA and commercial urea medium solutions compared to BBM standard medium. We cultivated the microalgae Chlorella sp in BBM, PA urea, and commercial urea media, evaluating their growth for 8 days. In addition, we appraised the cost of the culture media considering the quotation of the reagents and the mass used for pilot-scale cultivation (100I). It was possible to observe the similar growth of microalgae with urea PA and BBM. The use of urea PA as a culture media for microalgae has the potential to reduce the cost of the medium by $68 \%$. Thus, the cultivation of Chlorella in urea medium represents an alternative to reduce the production costs of biomass from this microorganism.
\end{abstract}

Keywords: Low-Cost Medium. Urea. Chlorella. Microalgae biomass.

\section{Instroduction}

Microalgae biomass has been applied in several processes, such as in the production of food, medicines, animal feed, fertilizers, biofuels, bioplastics, among others. Microalgae, such as Chlorella sp, stand out for their biological characteristics and biotechnological applications [1]. The bio-fixation of carbon dioxide makes it possible to apply microalgae in a sustainable remediation process due to the photosynthetic capacity of these microorganisms [2].

In recent years, much interest has been focused on the biotechnological potential of microalgae, mainly due to the identification of several substances synthesized by these organisms [3]. Some species of microalgae, such as species from the genera Chlorella and Arthrospira (Spirulina) are commercially cultivated due to their industrial applications [1,2].

Several studies progress demonstrated the potential for large-scale production of microalgal biomass, but several challenges persist to turn it economically viable. So, the development

Received on 23 May 2021; revised 28 July 2021.

Address for correspondence: Pablo Augusto Gulhões. SENAI CIMATEC. Avenida Orlando Gomes, Número 1845 - Piatã, Zip Code: 41650-010, Salvador, Bahia, Brazil. E-mail: pablo. silva@ba.estudante.senai.br.

J Bioeng. Tech. Appl. Health 2021;4(3):90-94.

(C) 2021 by SENAI CIMATEC. All rights reserved. of low-cost culture media and more efficient photobioreactors, improvements in nutrient use efficiency, and photosynthetic rate optimization represent some of these challenges [4].

In this context, the development of alternative culture media using urea as a source of nitrogen (N) for the cultivation of microalgae represents an attractive alternative to reduce the cost of production of microalgae biomass $[4,5]$ but it is necessary to evaluate the costs in detail. Some alternatives for cost reduction can already be found in use and have been extensively investigated, such as the use of NPK fertilizer [4] and the cultivation in wastewater [6]. On the other hand, an investigation of nitrogen-only sources is still poorly investigated as an alternative for cultivation [4].

The objective of this work was to evaluate the growth of the microalgae Chlorella sp in urea solution (pure commercial reagent) compared to BBM medium, as well as the costs involved in these culture media.

\section{Materials and Methods}

The experiments with the BBM, PA, and commercial urea media formulations were performed in parallel. Table 1 and Table 2 show the composition of stock solution and BBM media. We prepared PA and commercial urea solutions at a concentration of $1 \mathrm{~g}$ per liter. $180 \mathrm{~mL}$ of each culture medium in duplicate was added to an 
Table 1. Composition of stock solution and BBM media.

\begin{tabular}{lccc}
\hline Reagent & \multicolumn{2}{c}{ Stock Solution } & $\begin{array}{c}\text { Media } \\
\text { mL per } \mathbf{~}\end{array}$ \\
\hline $\mathrm{KH}_{2} \mathrm{PO}_{4}$ & 8.75 & Vol (mL) & 10 \\
$\mathrm{CaCl}_{2} .2 \mathrm{H}_{2} \mathrm{O}$ & 6.25 & 500 & 1 \\
$\mathrm{MgSO}_{4} .7 \mathrm{H}_{2} \mathrm{O}$ & 18.75 & 250 & 1 \\
$\mathrm{NaNO}_{3}$ & 62.5 & 250 & 1 \\
$\mathrm{~K}_{2} \mathrm{HPO}_{4}$ & 18.75 & 250 & 1 \\
$\mathrm{NaCl}_{\mathrm{Na} . \mathrm{EDTA} .2 \mathrm{H}_{2} \mathrm{O} /}$ & 6.25 & 250 & 1 \\
$\mathrm{KOH}$ & 2.5 & 250 & 1 \\
$\mathrm{Trace}_{\mathrm{Metal} \text { solution }}$ & 1.55 & 250 & 1 \\
$\mathrm{H}_{3} \mathrm{BO}_{3}$ & & 250 & 0.7 \\
$\mathrm{FeSO}_{4} 7 \mathrm{H}_{2} \mathrm{O}$ solution & 5.98 & & 1 \\
and $\mathrm{H}_{2} \mathrm{SO}_{4}(1 \mathrm{~mL})$ & & 500 & 1 \\
\hline
\end{tabular}

Table 2. Metal Trace solution (BBM media)

\begin{tabular}{lcc}
\hline Reagent & \multicolumn{2}{c}{ Stock Solution } \\
& Mass (g) & Vol (mL per L) \\
\hline $\mathrm{H}_{3} \mathrm{BO}_{3}$ & 2.86 & 1 \\
$\mathrm{MnCl}_{2} .4 \mathrm{H}_{2} \mathrm{O}$ & 1.81 & 1 \\
$\mathrm{ZnSO}_{4} .7 \mathrm{H}_{2} \mathrm{O}$ & 0.222 & 1 \\
$\mathrm{NaMoO}_{4} .2 \mathrm{H}_{2} \mathrm{O}$ & 0.39 & 1 \\
$\mathrm{CuSO}_{4} 5 \mathrm{H}_{2} \mathrm{O}$ & 0.079 & 1 \\
$\mathrm{Co}\left(\mathrm{NO}_{3}\right)_{4} .6 \mathrm{H}_{2} \mathrm{O}$ & 0.0494 & 1 \\
\hline
\end{tabular}

Erlenmeyer flask and autoclaved. The inoculum with $20 \mathrm{~mL}$ of Chlorella sp under sterile conditions and aliquots of the solutions were evaluated by density optical (DO) analysis through absorbance at $570 \mathrm{~nm}$ to infer the biomass growth over the 8 days.

The quotation with suppliers of each reagent used for culture media preparation performed the cost evaluation. After that, we took the arithmetic average of the reagent prices to obtain an average market price and the lower costs. In addition, we calculated the costs based on the reagents' mass values for a culture with a volume of $10 \mathrm{O} \mathrm{L}$, both for the BBM medium and PA and commercial urea.

\section{Results and Discussion}

Figure 1 shows similar growth rates for cultures with PA and BBM and lowers for commercial urea. Although the cultures show growth over the 8 days, further tests are needed on the quality and productivity of biomass.

Figure 1 shows the growth of algal biomass in urea solution, which indicates the possibility of using urea for other recurrent microalgae species, such as Arthrospira platensis (Spirulina). Spirulina is also a type of microalgae enlarged in industry and biotechnological processes [6], and the reduction of its cultivation cost can also contribute to the accessibility to a more sustainable process. 
Figure 1. Growth rate (DO/DO0 versus time) in culture media BBM and urea.

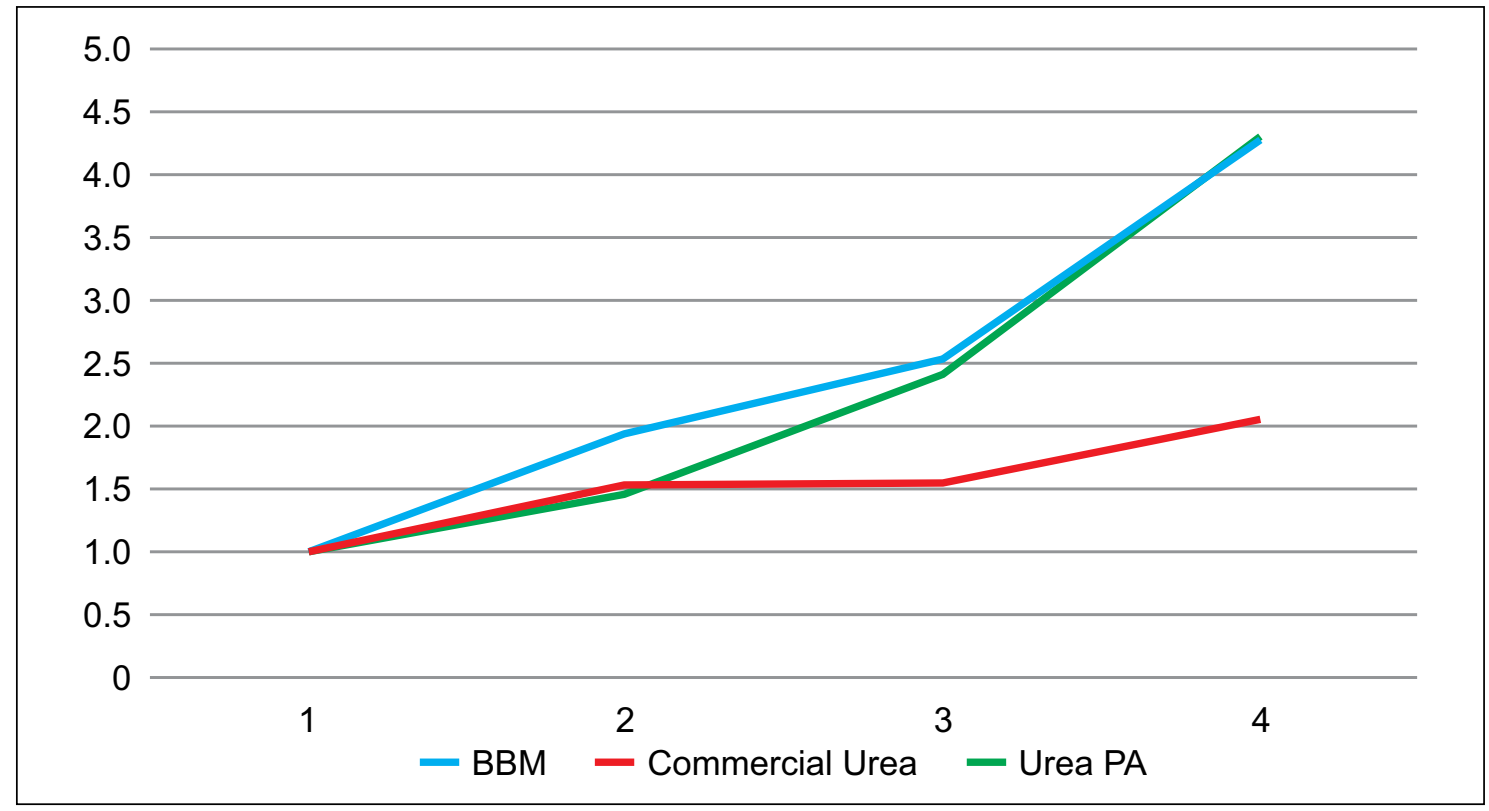

The urea PA has an average cost higher than the costs of the BBM medium and commercial urea because the suppliers quoted an imported reagent. However, when the minimum costs compared each reagent, the BBM media presented higher costs. Commercial urea had the lowest cost, but biomass growth is lower when compared to BBM culture media. Table 3 presents the costs to carry out a 100 L cultivation with BBM medium, while Figure 2 shows the average cost difference of BBM medium, PA urea, and commercial urea, while Figure 3 presents the cost difference based on the lower price of the same culture media, and Table 4 demonstrate the average and minor costs os cultivation media.

It is noteworthy that there is a high reduction in the average cost and the minimum cost for growing $100 \mathrm{~L}$ of culture medium (pilot scale). Depending on the results related to the quality of the biomass generated by urea, it will be possible to reduce by $68 \%$ the production cost of microalgae considering the lower cost of reagents (national). Ribeiro and colleagues [3] evaluated the use of nitrogen sources for the cultivation of Chlorella sorokiniana. They found that replacing the nitrogen source with urea reduced $65 \%$ of the cost compared to the BG11 medium. Thus, these results were similar to the study carried out in this work.

Ramanna and colleagues [6], seeking to investigate the effectiveness of water from domestic effluents compared to nitrogen, observed that the biomass using urea is more viable in terms of quantity and quality of the product obtained. Therefore, in addition to analyzing the quality of algal biomass, it is also necessary to monitor the cultivation with commercial urea for a larger period, to assess whether the cultivation cycle increases or if there is growth inhibition.

\section{Conclusion}

In this study, we get partial results for both the growth and the cost of the microalgae cultivation. Taken together, the results presented here indicate that the growth of Chlorella $\mathrm{sp}$ is similar in the BBM and urea PA and for commercial urea the growth rate is minor. The costs evaluation of the different media indicates that the replacement of the nitrogen source by urea PA can reduce the cost of the medium by $68 \%$. Further studies are needed to evaluate the quality of biomass produced with this low-cost culture media. 
Table 3. Example of calculation of the cost of reagents for BBM medium.

\begin{tabular}{lcc}
\hline Reagent & Mass for 100 L in g & Cost for 100 L (R\$) \\
\hline $\mathrm{MgSO}_{4} .7 \mathrm{H}_{2} \mathrm{O}$ & 7.5 & 0.23 \\
$\mathrm{NaCL}$ & 2.5 & 0.07 \\
$\mathrm{~K}_{2} \mathrm{HPO}_{4}$ & 7.5 & 0.80 \\
$\mathrm{KH}_{2} \mathrm{PO}_{4}$ & 1.75 & 0.17 \\
$\mathrm{CaCl}_{2} .2 \mathrm{H}_{2} \mathrm{O}$ & 2.5 & 0.14 \\
$\mathrm{Na}_{2} \mathrm{EDTA}$ & & 0.09 \\
$\mathrm{FeSO}_{4} 7 \mathrm{H}_{2} \mathrm{O}$ & 0.498 & 0.02 \\
$\mathrm{H}_{3} \mathrm{BO}_{3}$ & 1.436 & 0.08 \\
$\mathrm{Co}_{2}\left(\mathrm{NO}_{3}\right)_{2} .6 \mathrm{H}_{2} \mathrm{O}$ & 0.0079 & 0.01 \\
$\mathrm{MnCl}_{2} .4 \mathrm{H}_{2} \mathrm{O}$ & 0.181 & 0.15 \\
$\mathrm{ZnSO}_{4} .7 \mathrm{H}_{2} \mathrm{O}$ & 0.0222 & 0.00 \\
$\mathrm{CuSO}_{4} 5 \mathrm{H}_{2} \mathrm{O}$ & 0.0079 & 0.00 \\
$\mathrm{NaMoO}_{4} 2 \mathrm{H}_{2} \mathrm{O}$ & 0.039 & 0.01 \\
$\mathrm{NaNO}_{3}$ & 2.5 & 0.13 \\
$\mathrm{H}_{2} \mathrm{SO}_{4}$ & 0.1 & 6.08 \\
$\mathrm{KOH}$ & 0.62 & 0.07 \\
\hline
\end{tabular}

Figure 2. Cost of culture media.

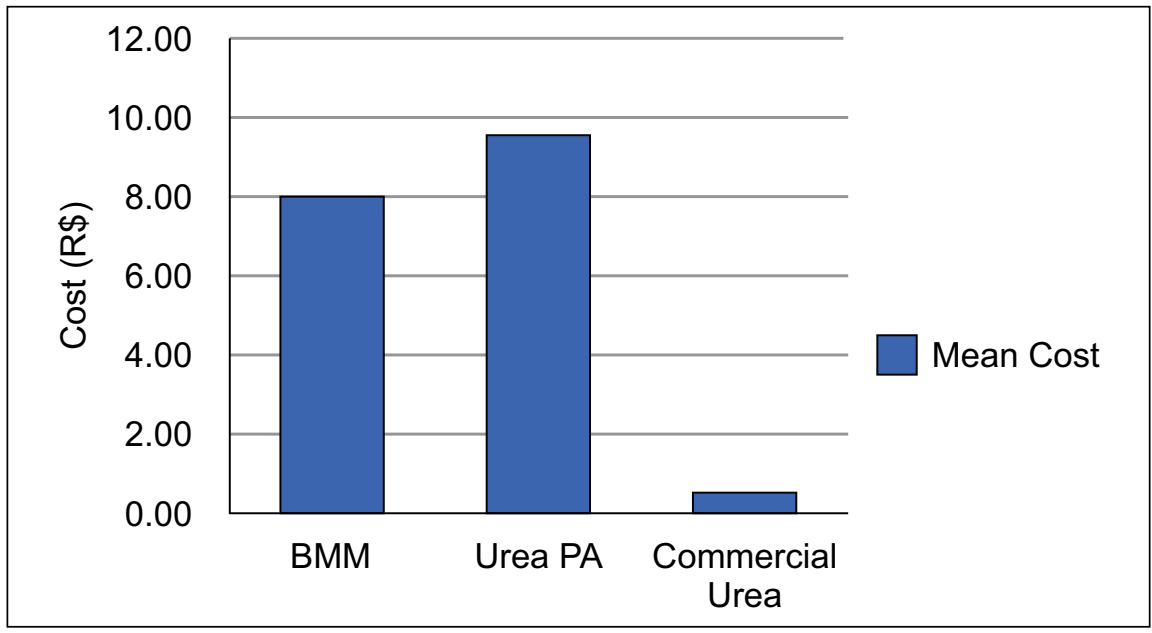

Figure 3. Lower cost of culture media.

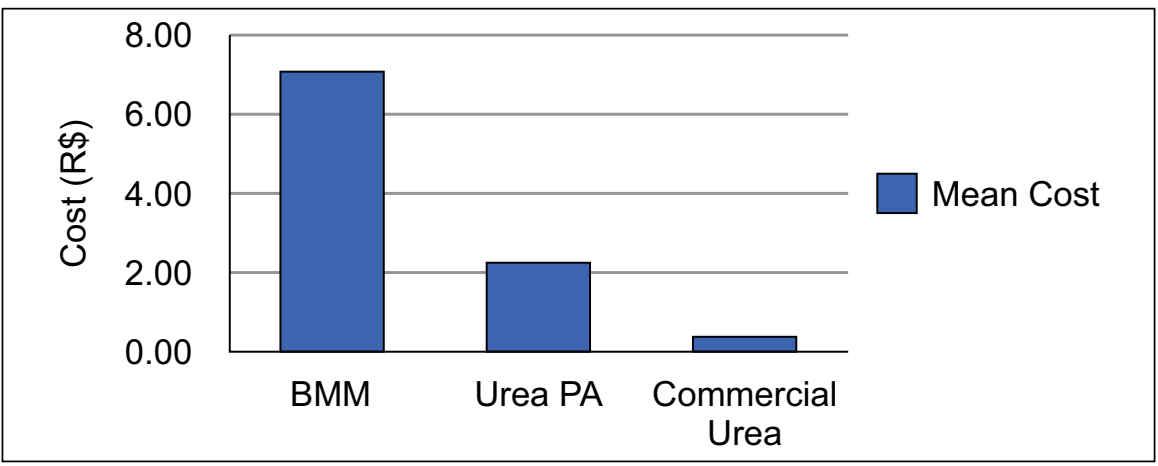


Table 4. Average cost and minor cost of cultivation media.

\begin{tabular}{lccc}
\hline & BMM & Urea PA & $\begin{array}{c}\text { Commercial } \\
\text { Urea }\end{array}$ \\
\hline Average cost $(\mathrm{R} \$)$ & 8.06 & 9.55 & 0.50 \\
Minor cost $(\mathrm{R} \$)$ & 7.06 & 2.24 & 0.35 \\
\hline
\end{tabular}

\section{References}

1. Borba VIA, Ferreira CLS. Cianobactéria Arthrospira (Spirulina) Platensis: Biotecnologia e Aplicações. Centro de Pós-graduação, Pesquisa e Extensão Oswaldo Cruz. p. 1-23. 2018.

2. Schmitz R, Magro CD, Colla LM. Aplicações ambientais de microalgas. Revista CIATEC-UPF 2012;(4)1:48-60.

3. Rizwan M, Mujtaba G, Menon SA, et al. Exploring the potential of microalgae for new biotechnology applications and beyond: A review, Renewable, and Sustainable Energy Reviews 2018;(92).

4. Ribeiro DM, Roncaratti LF, Possa GC, et al. A lowcost approach for Chlorella sorokiniana production through combined use of urea, ammonia and nitrate based fertilizers, Bioresource Technology Reports 2020;(9).

5. Prabaharan D, Uma L, Mathimani T. Formulation of low-cost seawater medium for high cell density and high lipid content of Chlorella vulgaris BDUG 91771 using central composite design in biodiesel perspective. Journal of Cleaner Production 2018;(2)198:575-586.

6. Ramanna L, Guldhe A, Rawat I, Bux F. The optimization of biomass and lipid yields of Chlorella sorokiniana when using wastewater supplemented with different nitrogen sources. Institute for Water and Wastewater Technology, Durban University of Technology, 27 March 2014. 